Goldschmidt 2021 Abstract

https://doi.org/10.7185/gold2021.3810

\section{The definition of geochemical background values at local scale as a key procedure to set reliable guidelines for contaminated land management.}

ANNALISE GUARINO ${ }^{1}$, ANTONIO PIZZOLANTE ${ }^{2}$, FEDERICO NICODEMO $^{2}$, GIANLUCA RAGONE ${ }^{3}$, AMEDEO D'ANTONIO ${ }^{4}$, ANGELO FERRARO ${ }^{4}$ AND STEFANO ALBANESE ${ }^{1}$

${ }^{1}$ University of Naples Federico II

${ }^{2}$ Istituto Zooprofilattico Sperimentale del Mezzogiorno

${ }^{3}$ Agenzia Regionale per la Prevenzione e l'Ambiente Campania

${ }^{4}$ Regione Campania

Presenting Author: annalise.guarino@unina.it

In Campania region, southern Italy, a geochemical prospecting activity focused on soils (topsoils and bottom soils) was completed within the frame of a regional-wide environmental project (www.campaniatrasparente.it). The study led to discriminate areas with high concentrations of some potentially toxic elements (PTEs) with a high probability to be geogenic rather than anthropogenic [1]. In facts, the plain around Mt. Somma-Vesuvius is one of the areas where the Enrichment Factor (EF) of $\mathrm{As}, \mathrm{Be}, \mathrm{V}, \mathrm{Tl}, \mathrm{Cu}$ and $\mathrm{Zn}$ resulted below 2 denoting a non-anthropic origin.

For this area, we statistically analysed geochemical data to determine local background concentrations and to set reference values (i.e. Upper Background Limit - UBL) to be used as guidelines to start site-specific characterization procedures.

Prior to elaborations, records in the dataset were subdivided according to the lithologies to which the related soil samples belong (Fig.1a). Subsequently, four different methods were applied to determine UBLs and results were compared to select the best solution to be potentially adopted as a local reference.

Specifically, methods were based on I) the use of a robust statistical estimator such as the Median Absolute Deviation (MAD), II) the assessment of $95 \%$ percentile (95P) and maximum (MAX) values among all records with an $\mathrm{EF}<2$, III) the application of Multifractal IDW [2] and zonal statistics, IV) the procedures released by the National System for Environmental Protection (SNPA).

Results obtained by the application of the four different methods generated similar UBLs, which, in general, were found to be higher than the guideline values (CSC) set by the national environmental legislation for the considered PTEs (Fig. 1b-g).

Our findings highlighted how, for a single element, the use of a single guideline value at national scale is not adequate to manage the remediation of potentially contaminated lands, especially in geologically/pedologically complex regions where the geogenic contribution to the compositional characteristic of soils is often peculiar and significant.

[1] De Vivo, Cicchella, Lima, Fortelli, Guarino, Zuzolo, Esposito, Cerino, Pizzolante \& Albanese (2021), Aracne Editrice, ISBN: 978-88-255-4036-9.
[2] Lima, De Vivo, Cicchella, Cortini \& Albanese (2003), Applied Geochemistry 18, 1853-1865.
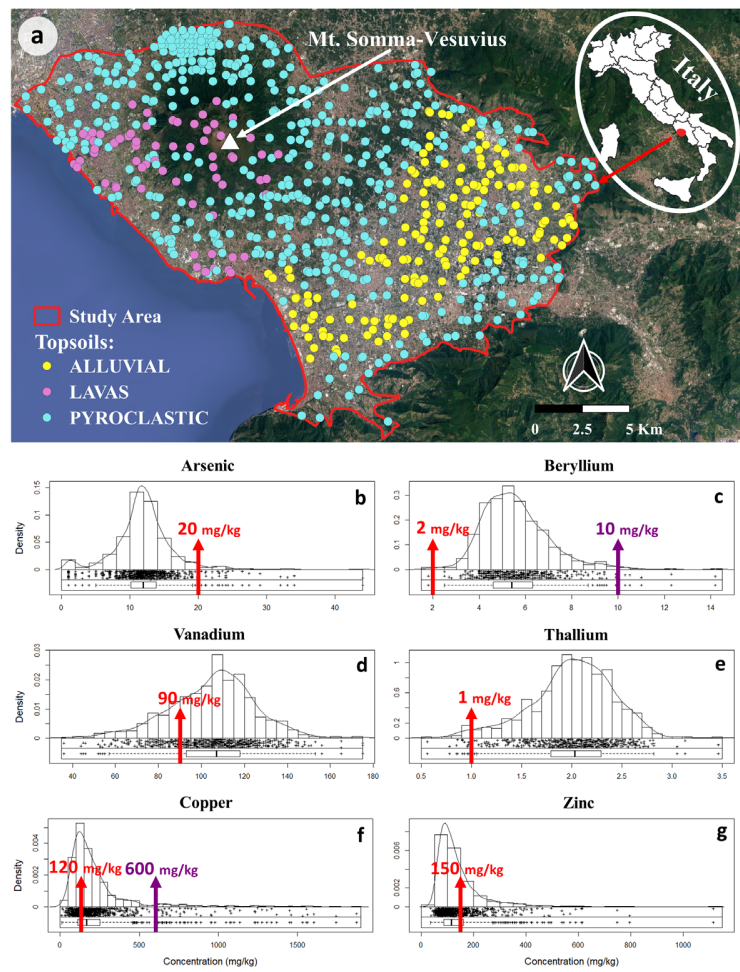

Figure 1. a) Geographical framework of the study area, location of the topsoil samples and their subdivision according to the lithologies. b-g) Edaplots (combination of histogram, density trace, onedimensional scattergram and boxplot) of $\mathrm{As}, \mathrm{Be}, \mathrm{V}, \mathrm{Tl}, \mathrm{Cu}$ and $\mathrm{Zn}$; the guideline values set by the nationa environmental legislation for residential land-use are indicated in red, for commercial land-use in purple. 